\title{
Identification of four novel PMM2 mutations in congenital disorders of glycosylation (CDG) Ia French patients
}

Sandrine Vuillaumier-Barrot, Gilles Hetet, Anne Barnier, Thierry Dupré, Maryvonne Cuer, Pascale de Lonlay, Valérie Cormier-Daire, Geneviève Durand, Bernard Grandchamp, Nathalie Seta

Biochimie A, Hôpital Bichat-Claude Bernard, 46 rue Henri Huchard, 75877 Paris Cedex 18, France

$S$ Vuillaumier- Barrot A Barnier

T Dupré

M Cuer

G Durand

N Seta

INSERM U409, Faculté de Médecine X Bichat, 75870 Paris Cedex 18, France

G Hetet

B Grandchamp

Pediatrics, Hôpital Necker, 75743 Paris Cedex 15, France

P de Lonlay

Genetics, Hôpital Necker, 75743 Paris Cedex 15, France

V Cormier-Daire

Biochimie Hormonale et Génétique, Hôpital Bichat-Claude

Bernard, 75877 Paris

Cedex 18, France

B Grandchamp

Laboratoire de Santé Publique, Faculté de Pharmacie, Paris V, 75270 Paris Cedex, France

N Seta

Correspondence to: Dr Seta, nathalie.seta@ bch.ap-hop-paris.fr

Revised version received 14 February 2000

Accepted for publication

17 April 2000

\begin{abstract}
We screened 11 unrelated French patients with congenital disorders of glycosylation (CDG) Ia for PMM2 mutations. Twenty one missense mutations on the 22 chromosomes $(95 \%)$ including four novel mutations were identified: C9Y (G26A) in exon 1, L32R (TA95GC) in exon 2, and T226S (C677G) and C241S (G722C) in exon 8. We studied the PMM activity of these four novel mutant proteins and of the $\mathrm{R} 141 \mathrm{H}$ mutant protein in an $E$ coli expression system. The T226S, C9Y, L32R, and C241S mutant proteins have decreased specific activity ( 23 to $41 \%$ of normal), are all more or less thermolabile, and R141H has no detectable activity. Our results indicate that the new mutations identified here are less severe than the inactive R141H mutant protein, conferring residual PMM activity compatible with life.

(F Med Genet 2000;37:579-580)
\end{abstract}

Keywords: CDG; phosphomannomutase; $P M M 2$ mutations

Congenital disorder of glycosylation, previously called carbohydrate deficient glycoprotein syndrome (CDG) Ia (OMIM 212065), is an autosomal recessive disorder characterised by central nervous system dysfunction and multiorgan failure owing to defective serum glycoprotein N-glycosylation, phosphomannomutase (PMM) deficiency, and mutations in the PMM2 gene. ${ }^{1}$ PMM 2 gene mutations have been described in white CDG Ia patients ${ }^{2-4}$ and in two Japanese families. ${ }^{5}$ A total of 27 different

\begin{tabular}{|c|c|c|c|c|c|}
\hline Identification & PMM activity & Mutation 1 nucleotide & $\begin{array}{l}\text { Mutation } 1 \\
\text { amino acid }\end{array}$ & Mutation 2 nucleotide & $\begin{array}{l}\text { Mutation } 2 \\
\text { amino acid }\end{array}$ \\
\hline$\overline{\mathrm{PL}}$ & 0.9 (le), 2.3 (ly) & G26A (exon 1) & C9Y & G425A (exon 5) & $\mathrm{R} 141 \mathrm{H}$ \\
\hline Co A & 0.1 (f) & TA95GC (exon 2) & L32R & ? & ? \\
\hline MT & $<0.1$ (f) & G385A (exon 5) & V129M & G425A (exon 5) & $\mathrm{R} 141 \mathrm{H}$ \\
\hline HA & $<0.1(\mathrm{f})$ & T395C (exon 5) & I132T & G368A (exon 5) & R123Q \\
\hline $\mathrm{DL}$ & $<0.1(\mathrm{f}),<0.1(\mathrm{le})$ & T395C (exon 5) & $\mathrm{I} 132 \mathrm{~T}$ & G425A (exon 5) & $\mathrm{R} 141 \mathrm{H}$ \\
\hline $\mathrm{PA}$ & ND & T395C (exon 5) & $\mathrm{I} 132 \mathrm{~T}$ & G425A (exon 5) & $\mathrm{R} 141 \mathrm{H}$ \\
\hline SD & $0.5(\mathrm{f}),<0.1(\mathrm{le})$ & C677G (exon 8) & $\mathrm{T} 226 \mathrm{~S}$ & G425A (exon 5) & $\mathrm{R} 141 \mathrm{H}$ \\
\hline GL & $<0.1$ (f) & G691A (exon 8) & V231M & G425A (exon 5) & $\mathrm{R} 141 \mathrm{H}$ \\
\hline PJ & $<0.1$ (f) & G691A (exon 8) & V231M & G425A (exon 5) & $\mathrm{R} 141 \mathrm{H}$ \\
\hline $\mathrm{Ch} \mathrm{A}$ & $0.5(\mathrm{f})$ & G691A (exon 8) & $\mathrm{V} 231 \mathrm{M}$ & $\mathrm{G} 425 \mathrm{~A}($ exon 5$)$ & $\mathrm{R} 141 \mathrm{H}$ \\
\hline $\mathrm{RN}$ & $<0.1(\mathrm{le})$ & G722C (exon 8) & C241S & G425A (exon 5) & $\mathrm{R} 141 \mathrm{H}$ \\
\hline
\end{tabular}

$\mathrm{ND}=$ not determined

? = no mutations found in cDNA and intron-exon junctions. missense mutations and a single base pair deletion have been reported. Most of the mutations are located in exons 5 and 8, and most of the patients are compound heterozygotes. We screened 11 previously unreported unrelated French patients with CDG Ia for mutations and studied the PMM activity of the new mutant proteins in an $E$ coli expression system.

\section{Methods}

PATIENTS

Eleven unreported CDG Ia French patients were included in the study. Blood, cultured fibroblasts from forearm biopsy and/or lymphoblasts were referred to our laboratory for enzyme assay and molecular diagnosis.

SEQUENCING AND RESTRICTION ANALYSIS

RNA and DNA were isolated from fresh blood overlapping fragments were obtained from mRNA using RT-PCR and were sequenced on both strands. The intron-exon junctions were also sequenced in some patients after PCR from genomic DNA using available intronic primers. ${ }^{2}$ Mutations were confirmed by restriction analysis of genomic DNA (excepted for C9Y, confirmed on cDNA) with mutagenic primers introducing diagnostic restriction sites, if necessary, and intronic primers.

CONSTRUCTS FOR EXPRESSION IN E COLI

Mutated cDNA was cloned into the expression plasmid pGEX-KG, thereby encoding a PMM-glutathione S-transferase (GST) fusion recombinant protein. The mutant and normal cDNAs were obtained by PCR from the cDNA or cultured fibroblasts of CDG Ia patients. Two 


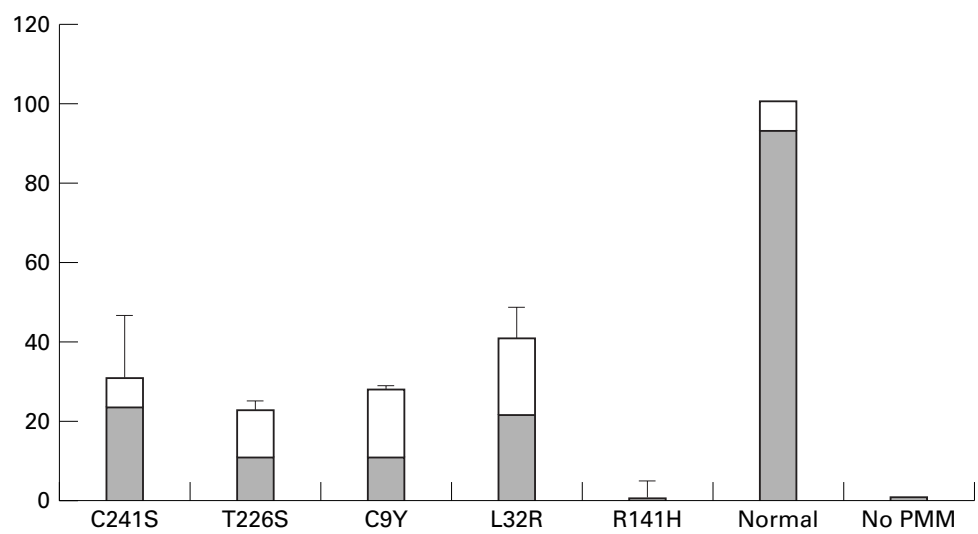

Figure 1 PMM activity of recombinant PMM2 proteins. The white bars are the mean (SD) ( $n>3)$ of the PMM2 protein activity expressed as a percentage of the normal enzyme. The grey bars show the residual PMM2 protein activities after heating at $46^{\circ} \mathrm{C}$ for five minutes.

of heterozygous patients, using the Boerhinger Expand High Fidelity PCR.

PHOSPHOMANNOMUTASE ASSAY

Clones were grown at $37^{\circ} \mathrm{C}$ overnight and bacterial cells were lysed by osmotic and mechanical shock. Expression of PMM2 protein in the cell lysate was checked by western blot analysis. The PMM activity of the recombinant proteins was assayed in the cell lysate, as described elsewhere. ${ }^{6}$ Thermolability was assessed by treating the lysates at $46^{\circ} \mathrm{C}$ for five minutes before determining activity. All assays were done at least in triplicate.

\section{Results and discussion}

Twenty one missense mutations were identified on the 22 chromosomes (95\%) (table 1). The most frequent mutation, $\mathrm{R} 141 \mathrm{H}$ in exon 5 , was found in nine $(41 \%)$ of the 22 chromosomes in keeping with previous data. ${ }^{2}$

Mutations I132T in exon 5 and V231M in exon 8 were each found three times (14\%). We did not find the F119L mutation, which was present in $16 \%$ of CDG Ia alleles from the 56 patients of different geographical origins ${ }^{2}$ and in $44 \%$ of CDG Ia alleles from the 18 Danish patients. ${ }^{3}$ This mutation thus seems to be more prevalent in northern Europe than in France. Furthermore, we observed a variety of mutations in this French population in contrast to the Scandinavian countries, where two mutations, $\mathrm{R} 141 \mathrm{H}$ and $\mathrm{F} 119 \mathrm{~L}$, accounted for $88 \%$ of all mutations, indicating a founder effect.

Four new mutations from living patients were identified: C9Y (G26A) in exon 1, L32R (TA95GC) in exon 2, and T226S (C677G) and C241S (G722C) in exon 8, which corresponds to the C-terminal portion of the protein. All described mutations are located in exons distant from exon 5. The C9Y mutation was found in exon 1, in which no mutations have previously been described, in two adult sibs.

We studied the PMM activity of the four novel mutant proteins and of the $\mathrm{R} 141 \mathrm{H}$ mutant protein in an $E$ coli expression system. All the clones expressed the recombinant PMM-GST protein to the same degree and with no change in the apparent molecular weight on western blotting (data not shown). The activity of the $\mathrm{R} 141 \mathrm{H}$ mutant protein was undetectable, with values no different from the control clone without PMM2 cDNA (fig 1). This result confirms the absence of residual PMM activity for the most frequent mutant protein, $\mathrm{R} 141 \mathrm{H}$, which would explain the lack of homozygotes for this mutation, as it is probably lethal. $^{7}$

The C241S, C9Y, L32R, and T226S mutant proteins exhibited 23 to $41 \%$ of the normal protein activity (fig 1). They were all more thermolabile than the control as they lost from 26 to $56 \%$ activity after heating at $46^{\circ} \mathrm{C}$ for five minutes, compared to $7 \%$ for the normal protein (fig 1).

Expression studies indicate that all the new mutations that we described in this paper affect $P M M 2$ activity but are less severe than $\mathrm{R} 141 \mathrm{H}$. These results may be related to the corresponding mutation localisation on the gene, distant from exon 5. Studies of the functional domain of phosphomannomutase are required to understand exactly how these mutations affect PMM2 protein function.

We are grateful to the patients and their families. This work was supported by a grant from Delegation à la Recherche Clinique, Assistance Publique-Hôpitaux de Paris (CRC 97139).

1 Matthijs G, Schollen E, Pardon E, Veiga-Da-Cunha M, Jaeken J, Cassiman JJ, Van Schaftingen E. Mutations in PMM 2, a phosphomannomutase gene on chromosome syndrome. Nat Genet 1997;16:88-92. (Published erratum syndrome. Nat Genet 1997;16:88-92.

2 Matthijs G, Schollen E, Van Schaftingen E, Cassiman JJ, Jaeken J. Lack of homozygotes for the most frequent disease allele in carbohydrate-deficient glycoprotein syndrome type Ia. Am f Hum Genet 1998;62:542-50

3 Kjaergaard S, Skovby F, Schwartz M. Absence of homozygosity for predominant mutations in PMM2 in Danish patients with carbohydrate-deficient glycoprotein syndrome type 1. Eur F Hum Genet 1998;6:331-6.

4 Vuillaumier-Barrot S, Barnier A, Cuer M, Durand G, Grandchamp B, Seta N. Characterization of the $415 \mathrm{G}>\mathrm{A}$ (E139K) PMM2 mutation in carbohydrate-deficient glycoprotein syndrome type Ia disrupting a splicing enhancer resulting in exon 5 skipping. Hum Mutat 1999;14:543-4.

5 Kondo I, Mizugishi K, Yoneda Y, Hashimoto T, Kuwajima K, Yuasa I, Shigemoto K, Kuroda Y Missense mutations in , Yuasa I, Shigemoto K, Kuroda Y. Missense mutations in phosphomannomutase 2 gene in two Japanese families with Genet 1999;55:50-4.

6 Van Schafingen E, Jaeken J. Phosphomannomutase deficiency is cause of carbohydrate-deficient glycoprotein syndrome type I. FEBS Lett 1995;377:318-20.

7 Pirard M, Matthijs G, Heykants L, Schollen E, Grunewald $S$, Jaeken J, van Schaftingen E. Effect of mutations found in carbohydrate-deficient glycoprotein syndrome type Ia on the activity of phosphomannomutase 2. FEBS Lett 1999;452:319-22. 